the long term compared with other options for these patients.

A. Sampath Kumar, MCh All India Institute of Medical Sciences Department of Cardiothoracicl Vascular Surgery Ansari Nagar New Delhi, India

doi:10.1016/j.jtcvs.2009.09.001

\section{OPTIMAL SURGICAL}

APPROACH FOR REPAIR OF AORTOPULMONARY WINDOW WITH AORTIC ORIGIN OF THE RIGHT PULMONARY ARTERY

\section{To the Editor:}

We read with great interest the article titled "Single-Stage Repair of Aortopulmonary Window With Interrupted Aortic Arch by Transection of the Aorta and Direct Reconstruction" by Yoshida and associates. ${ }^{1}$

The authors describe a repair technique using autologous arterial wall tissue without artificial material for a patient with aortopulmonary window (APW), right pulmonary artery (RPA) originating from the ascending aorta, and interrupted aortic arch. However, the repair technique for APW and RPA originating from the ascending aorta totally coincides with our previously reported technique. ${ }^{2}$ Inasmuch as APW is a relatively uncommon congenital heart defect, to establish the universality of these kinds of procedures expecting the future growth potential of both the pulmonary artery and the aorta, it is necessary to accumulate widespread data related to the applicability and the late follow-up results.

Taking every step into consideration, the reconstruction of the pulmonary bifurcation is the most critical step in the procedure. Where on the ascending aorta of authors' patients did the RPA arise? As more dorsal and unequal partitioning of the aortopulmonary trunk by the conotruncal ridges is the embryogenesis of the APW associated with origin of the
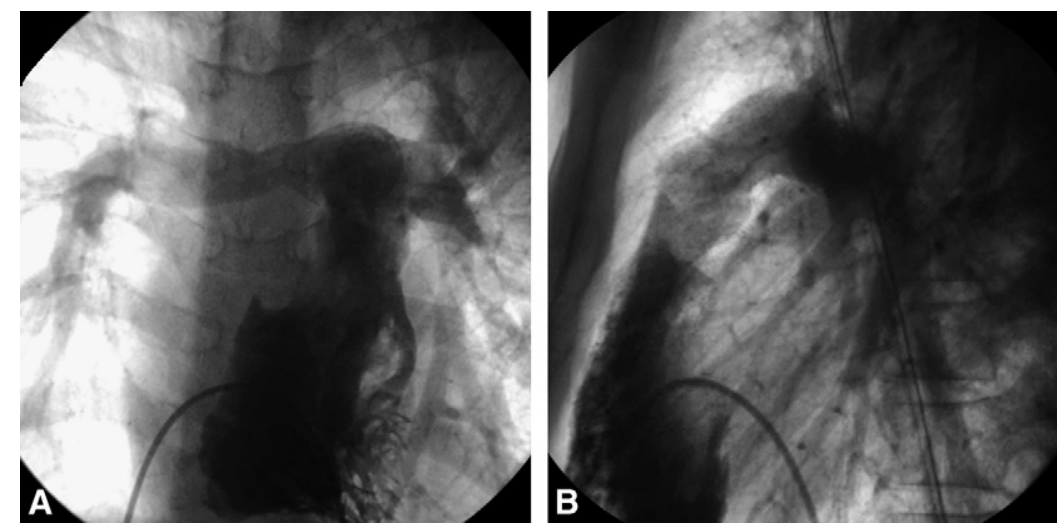

FIGURE 1. Right ventriculography 15 years after complete repair. These findings show sufficient growth and geometry of the reconstructed right pulmonary artery. Simultaneous cardiac catheterization exhibited that main pulmonary artery pressure is $25 / 7$ (12) $\mathrm{mm} \mathrm{Hg}$, and peripheral right pulmonary artery pressure 15/8 (10) $\mathrm{mm} \mathrm{Hg}$. A, Anteroposterior view. B, Lateral view.

RPA from the ascending aorta, ${ }^{3}$ the RPA commonly arises from the right posterolateral aspect of the ascending aorta, and the geometry would be better preserved by our technique with an extensive mobilization of both the aortic arch and the pulmonary arteries. Therefore, our technique seems to be impartially applicable to this combination. Consequently, as the authors noted in the article, we also agree that it can allow not only sufficient enlargement but also growth of the reconstructed arteries (Figure 1). ${ }^{2}$

We appreciate that our technique using only autologous arterial wall tissue was valid for a large APW extending to the proximal site of the pulmonary artery trunk from the pulmonary bifurcation and with the interrupted aortic arch. ${ }^{1}$ However, there are a few useful modifications of our technique: appropriately augmenting one of the reconstructed arteries with autologous pericardium is a good practical alternative to avoid a tense anastomosis of the reconstructed arteries in the individual geometry and associated lesions. ${ }^{4,5}$

We think that our technique using autologous arterial wall tissue is valid for any APW with aortic origin of the RPA, with some practical modifications, and good late results were also certified by this article.
Tetsuya Kitagawa, $M D, P h D$

Takashi Kitaichi, MD, PhD

Homare Yoshida, MD, PhD

Department of Cardiovascular Surgery

Institute of Health Biosciences The University of Tokushima Graduate School Tokushima, Japan

\section{References}

1. Yoshida M, Yamaguchi M, Oshima Y, Oka S, Higuma T, Okita Y. Single-stage repair of aortopulmonary window with interrupted aortic arch by transection of the aorta and direct reconstruction. $J$ Thorac Cardiovasc Surg. 2009;138:781-3.

2. Kitagawa T, Katoh I, Taki H, Wakisaka Y, Egawa Y, Takahashi Y, et al. New operative method for distal aortopulmonary septal defect. Ann Thorac Surg. 1991;51:680-2

3. Richardson JV, Doty DB, Rossi NP, Ehrenhaft JL. The spectrum of anomalies of aortopulmonary septation. J Thorac Cardiovasc Surg. 1979;78:21-7.

4. Abbruzzese PA, Merlo M, Chiappa E, Bianco R, Ferrero F, Cappone CM. Berry syndrome, a complex aortopulmonary malformation: one-stage repair in a neonate. Ann Thorac Surg. 1997;64:1167-9.

5. Codispoti M, Mankad PS. One-stage repair of interrupted aortic arch, aortopulmonary window, and anomalous origin of right pulmonary artery with autologous tissues. Ann Thorac Surg. 1998;66:264-7.

doi:10.1016/j.jtcvs.2009.08.053

\section{Reply to the Editor:}

We thank Dr Kitagawa for his thoughtful and informative comments 